\title{
Apocalypse Now en la palude italiana: Comacchio en una tarde dechiriquiana ${ }^{1}$
}

\author{
I ván MOURE PAZOS
}

Istituto di Studi Superiori / Università di Bologna

CIAUD / Faculdade de Arquitectura / Universidade de Lisboa

Departamento de Historia da Arte / Universidade de Santiago de Compostela ivan.menes@yahoo.es

Ferrara, 7 de julio de 2015, 52 grados de temperatura percibida. Nos encontramos atrapados en el verano más caluroso de la historia de Italia. Aquí nos hallamos, aquí nos ha puesto hoy la maldita providencia, en la llanura padana, en la sauna adriática de la Italia oriental. La humedad es insoportable y el aire acondicionado apenas refresca. Lo único que alivia nuestro sofoco es una bañera de agua fría a la que acudimos de manera reiterativa. Fuera, las cigarras gritan, pareciese de dolor. Los mosquitos tigre revolotean como en un filme de terror, diríase del género marabuntas. El asfalto de las calles se ablanda como gelatina y mi perro Ludwig se quema las patas al caminar. El silencio es absoluto, el sol abrasador. En un alarde de valentía sin límites, me precipito a la cancela de casa, parece que acabase de abrir la puerta de un enorme horno gigante. Tengo que retroceder, apenas puedo respirar. Convenzo a mi mujer para partir en coche hacia Comacchio y retratar este aciago día, del mismo modo que un reportero de guerra crea visiones de luz en la oscuridad de la desgracia. Semidesnudos, con varias garrafas de agua con hielo (más hielo que agua) y rociados de Autan (Potection Plus), decidimos partir para esta ciudad del Delta Po. El aire acondicionado del coche alivia pero, por momentos, creemos desfallecer. Tal hazaña solo puede ser valorada desde un enfoque performático. En veinte minutos llegamos, la ciudad está vacía; pura metafísica. En esta región padana, Chirico, Carrà, Morandi y de Pisis fundaron, hace cien años, aquel movimiento presurrealista que, andando el tiempo, revolucionaría la pintura contemporánea universal. En un momento de frescura, brisa y lucidez, me asalta una sentencia dechiriquiana: "Hay mucho más misterio en la sombra de un hombre caminando en un día soleado que en todas las religiones pasadas, presentes y futuras". Simplemente caminamos (¿o nos arrastramos?) y fotografiamos, inmortalizando el recuerdo de un día apocalíptico intitulado:

${ }^{1}$ El presente texto está basado en una historia real: todo lo expuesto ha tenido lugar durante la aciaga tarde del 7 de julio de 2015, en Ferrara y su Delta del Po. Asimismo, el siguiente ensayo forma parte del Proyecto de Investigación Internacional "Adriatic Coast to Coast", desarrollado en el Dipartimento di Architettura de la Università di Bologna. 
Apocalypse Now en la palude italiana. Ya se sabe que, en ocasiones, crece la creatividad al calor de las situaciones más adversas e incómodas: el arte como terapia y la superación de escollos. Las ruinas parecen más ruinas con este sol de justicia. ¡Qué razón tenía Wiesenthal!, "el caluroso verano es la época en que parecen más bellas las ruinas romanas". ¿Por qué será que lo antiguo se aquilata de melancolía y belleza en estos días de soledad y calor? O, formulado a la inversa - citando a un gran amigo-, ¿hay algo más triste que contemplar la Puerta de Isthar o el Altar de Pérgamo bajo el foco de ese plomizo cielo berlinés que se filtra, amenazante, tenebroso y desagradecido, por la cubierta del Pergamonmuseum? Visiones de soledad, calor abrasador y ruinas que, sin duda, han sido muy bien manejadas por Paolo Sorrentino en La grande bellezza (2013).

Ėccolo il Comacchio! Nos adentramos en un pueblo olvidado, bellísimo y decadente. Un enclave en proceso de desertización demográfica debido al incesante flujo migratorio de sus habitantes hacia zonas más prósperas - pero menos amables-, como bien pudiera ser el eje industrial emiliano conformado por la sempiterna triada empresarial: Módena, Parma y Bolonia. Aquí ya nadie vive de la pesca de la anguila, y ni siquiera el nombramiento, en 1999, de la región como Patrimonio de la Humanidad (UNESCO) ha conseguido reactivar un turismo completamente absorbido, en su totalidad, por la ciudad vecina de Venecia; ciudad esta más lustrosa y bizantina pero menos metafísica y propicia a las experiencias introspectivas que Comacchio. La humedad en la palude es descontrolada y cuesta coger aire para respirar. Buscamos sombras para aprehender luces. Lo que sigue es pura imagen; la parte más bella de un día de sudor, fatiga e hipotensión. ¿Acaso la transformación del sufrimiento en arte y belleza no es el principal motivo creador que subyace a la pulsión artística? ¿Acaso no conjuramos a la inmortalidad cuando creamos, venciendo así la resignante e ignominiosa idea de la muerte? En eso andábamos, sin poder siquiera pensar en la muerte, sintiéndola. 
MOURE PAZOS, Iván (2016): “Apocalypse Now en la palude italiana: Comacchio en una tarde dechiriquiana". Ángulo Recto. Revista de estudios sobre la ciudad como espacio plural, vol. 8, núm. 1-2, pp. 127-137. ISSN: 1989-4015.
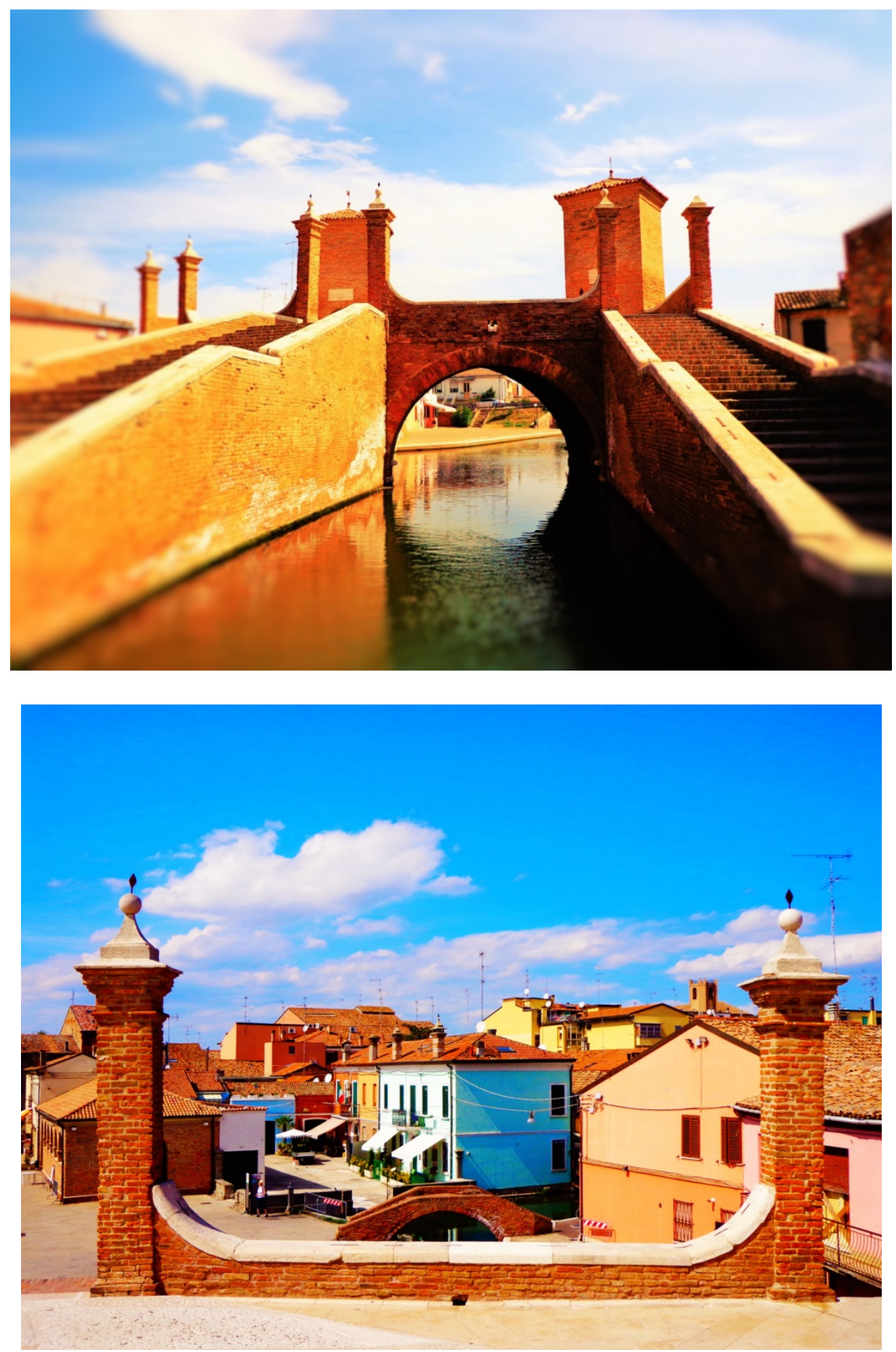
MOURE PAZOS, I ván (2016): “Apocalypse Now en la palude italiana: Comacchio en una tarde dechiriquiana". Ángulo Recto. Revista de estudios sobre la ciudad como espacio plural, vol. 8, núm. 1-2, pp. 127-137. ISSN: 1989-4015.
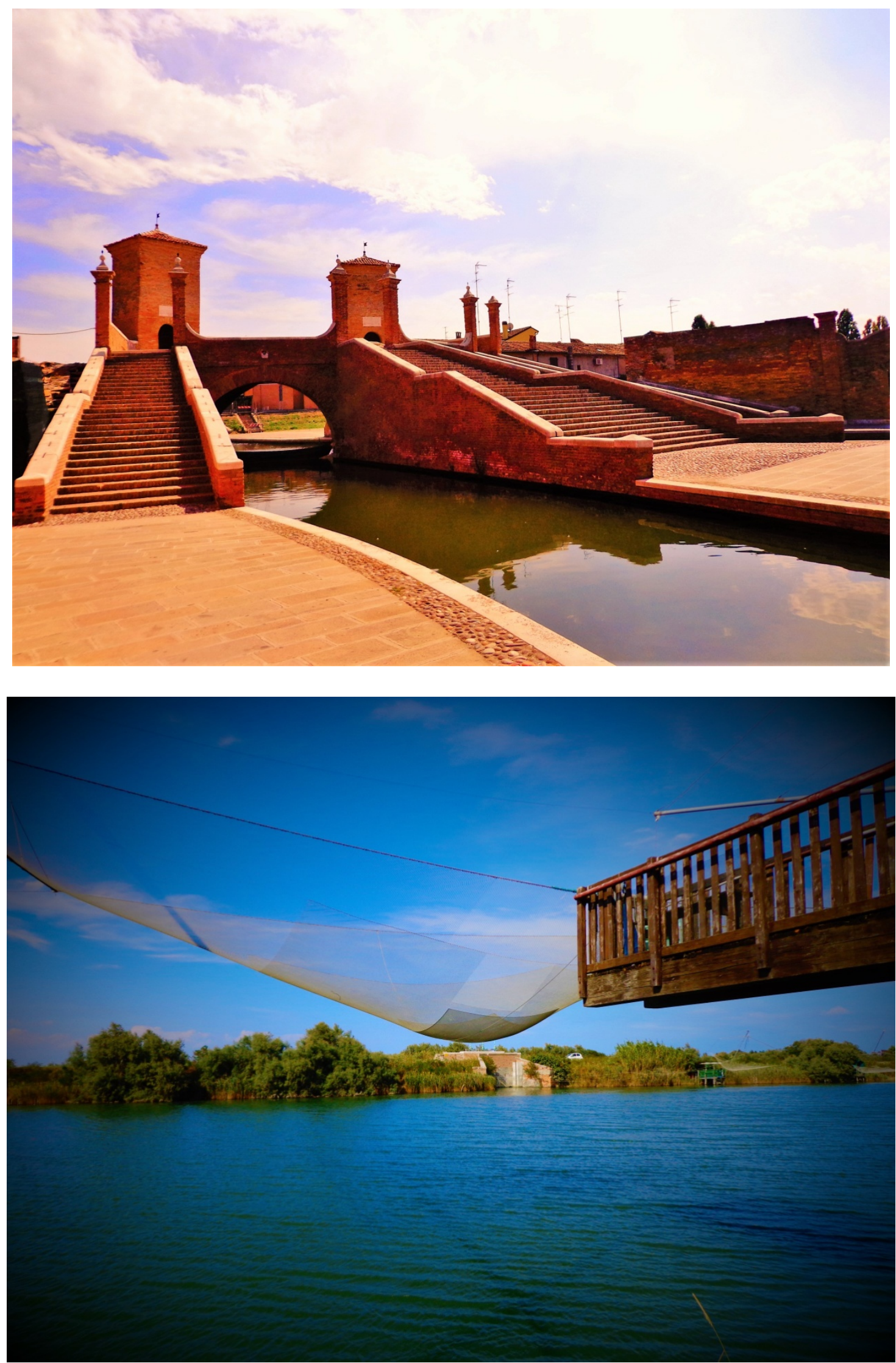
MOURE PAZOS, Iván (2016): “Apocalypse Now en la palude italiana: Comacchio en una tarde dechiriquiana". Ángulo Recto. Revista de estudios sobre la ciudad como espacio plural, vol. 8, núm. 1-2, pp. 127-137. ISSN: 1989-4015.
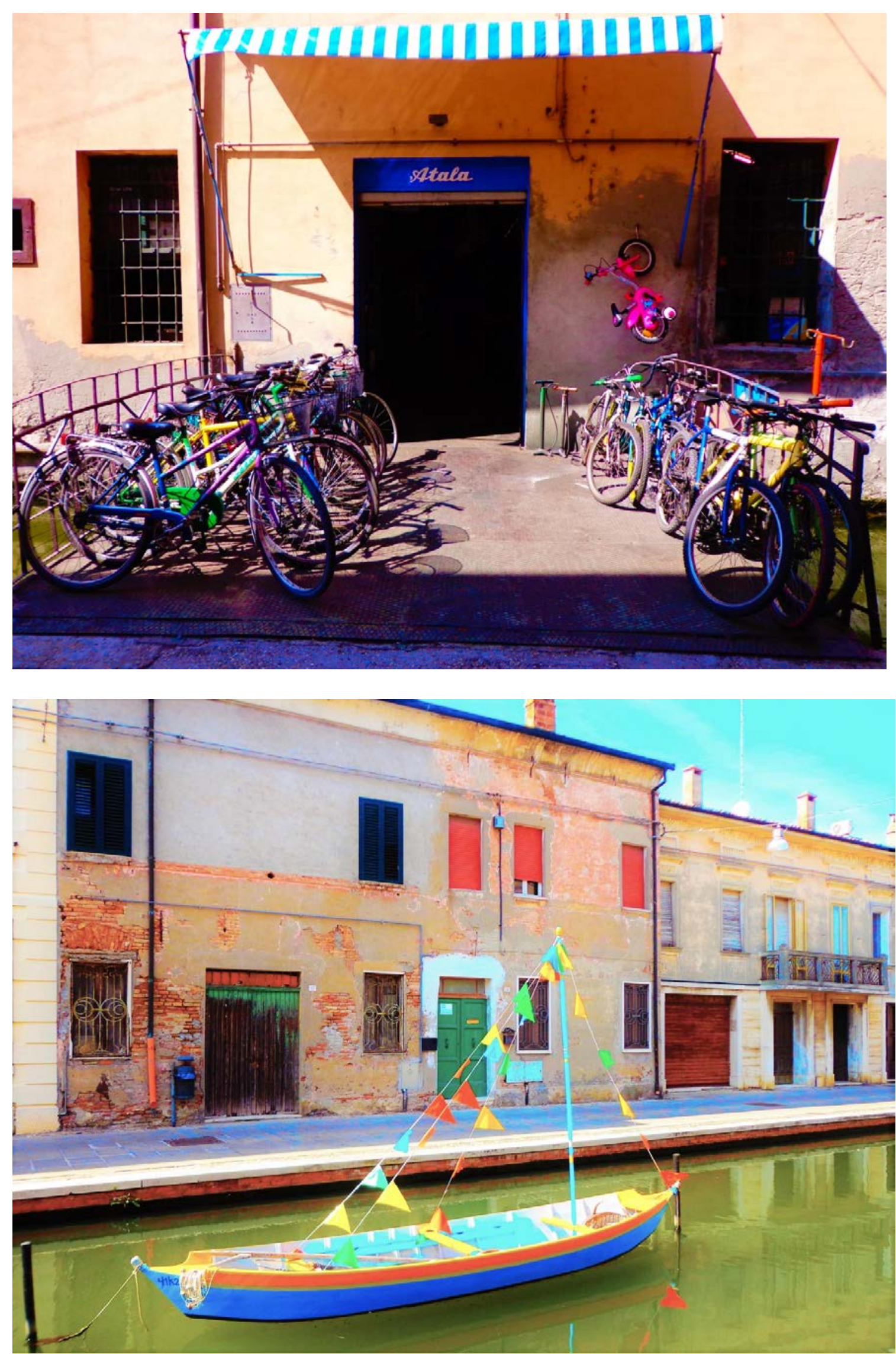
MOURE PAZOS, Iván (2016): “Apocalypse Now en la palude italiana: Comacchio en una tarde dechiriquiana". Ángulo Recto. Revista de estudios sobre la ciudad como espacio plural, vol. 8, núm. 1-2, pp. 127-137. ISSN: 1989-4015.
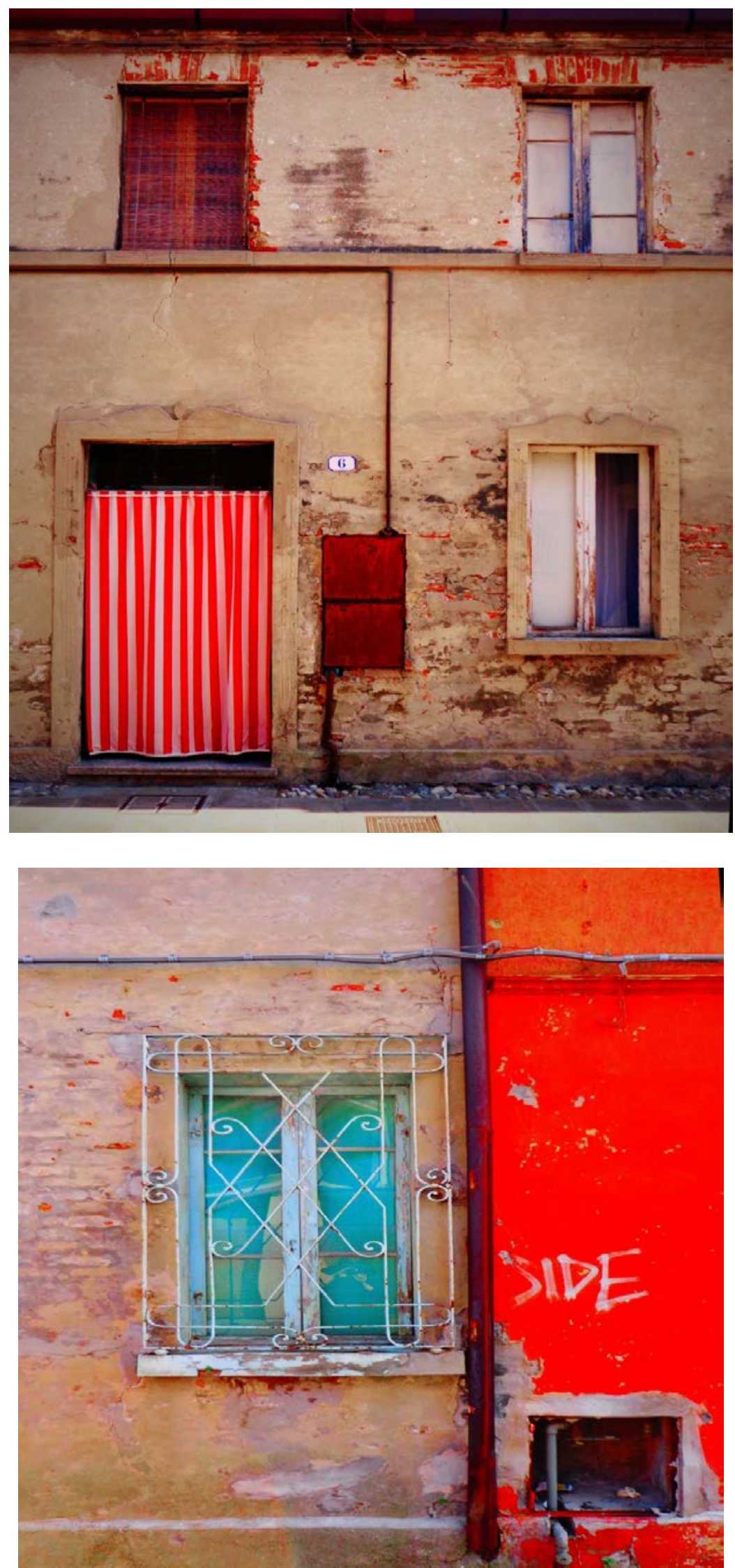
MOURE PAZOS, Iván (2016): “Apocalypse Now en la palude italiana: Comacchio en una tarde dechiriquiana". Ángulo Recto. Revista de estudios sobre la ciudad como espacio plural, vol. 8, núm. 1-2, pp. 127-137. ISSN: 1989-4015.

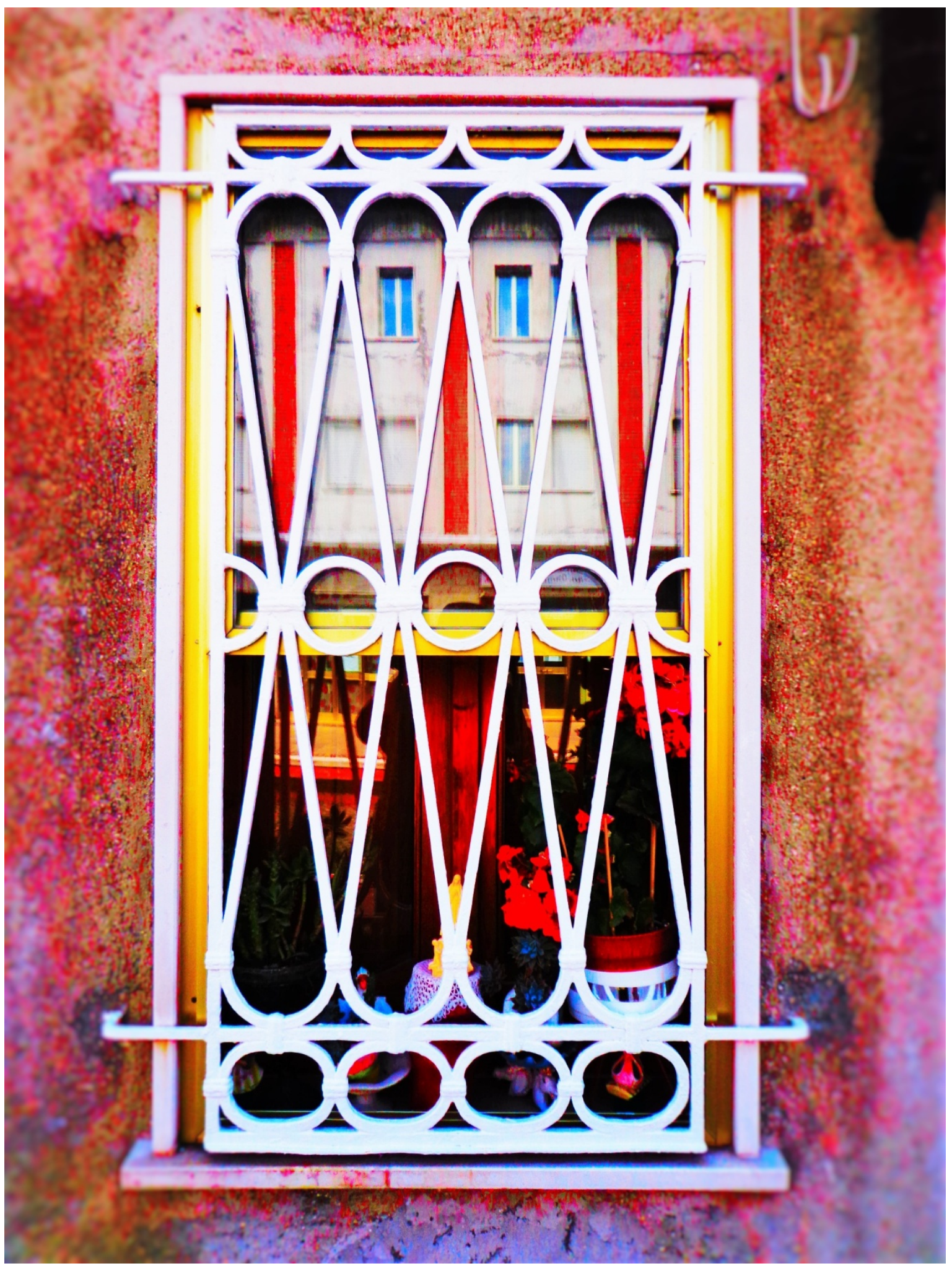


MOURE PAZOS, Iván (2016): “Apocalypse Now en la palude italiana: Comacchio en una tarde dechiriquiana". Ángulo Recto. Revista de estudios sobre la ciudad como espacio plural, vol. 8, núm. 1-2, pp. 127-137. ISSN: 1989-4015.
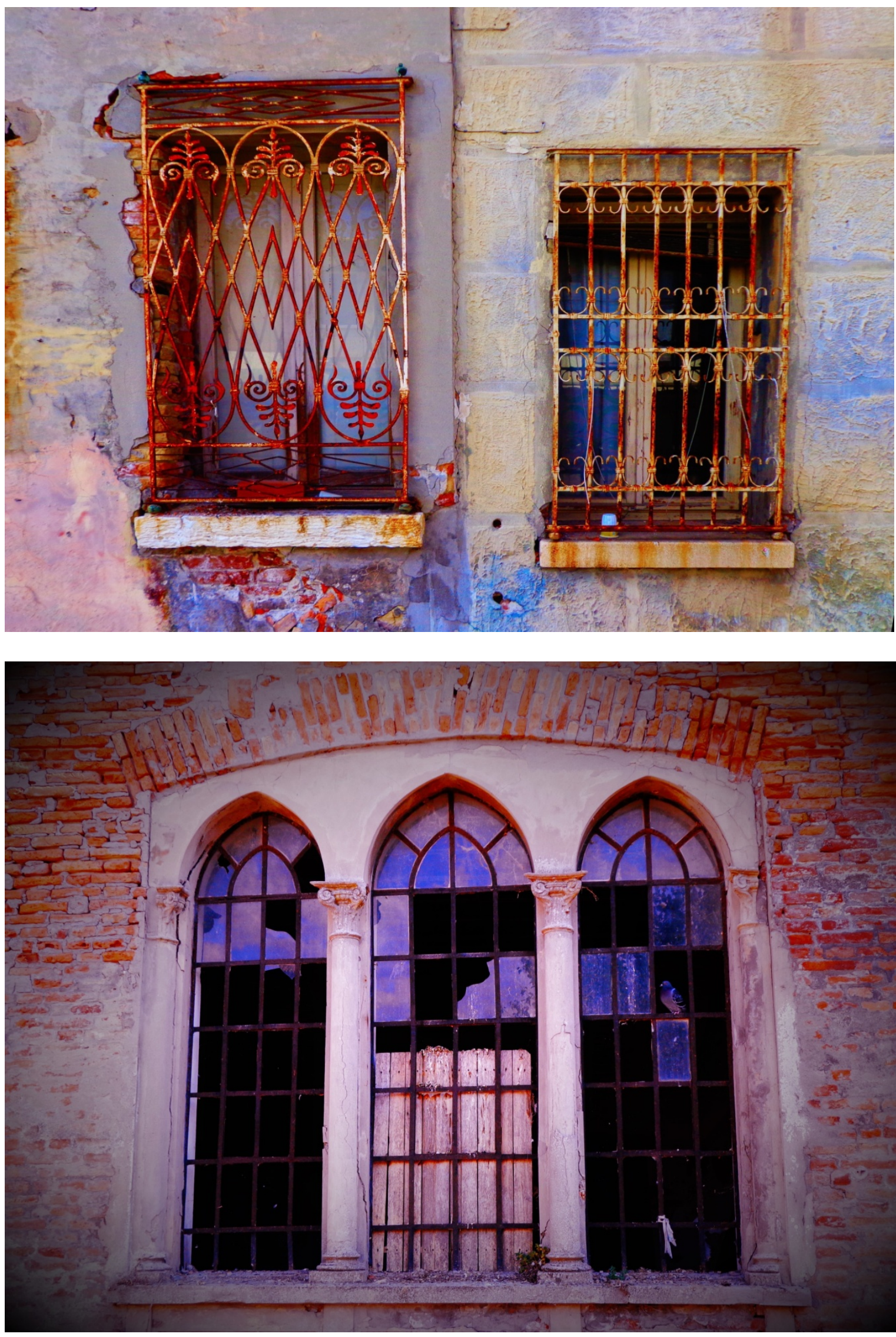
MOURE PAZOS, Iván (2016): “Apocalypse Now en la palude italiana: Comacchio en una tarde dechiriquiana". Ángulo Recto. Revista de estudios sobre la ciudad como espacio plural, vol. 8, núm. 1-2, pp. 127-137. ISSN: 1989-4015.

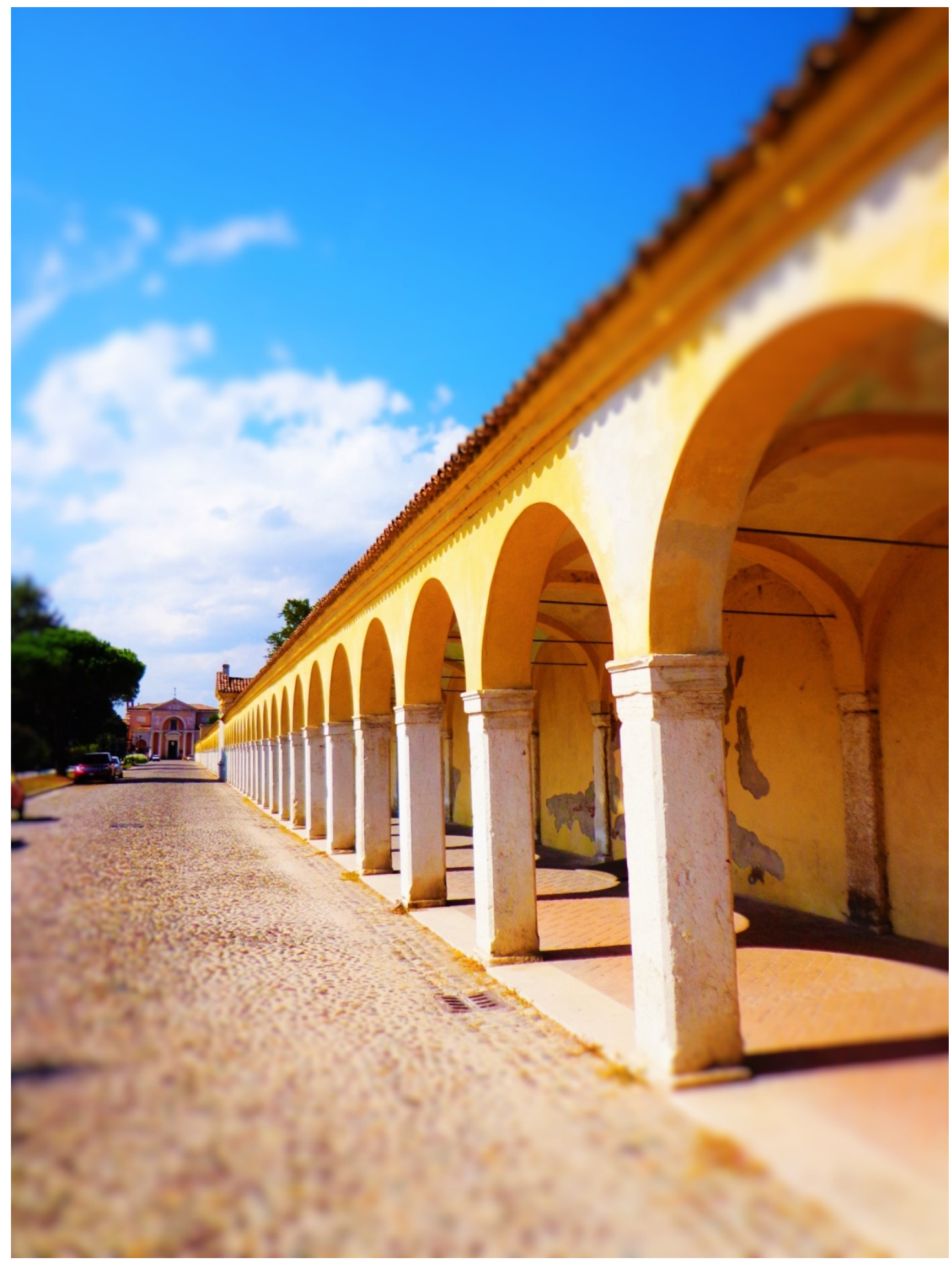


MOURE PAZOS, Iván (2016): “Apocalypse Now en la palude italiana: Comacchio en una tarde dechiriquiana". Ángulo Recto. Revista de estudios sobre la ciudad como espacio plural, vol. 8, núm. 1-2, pp. 127-137. ISSN: 1989-4015.

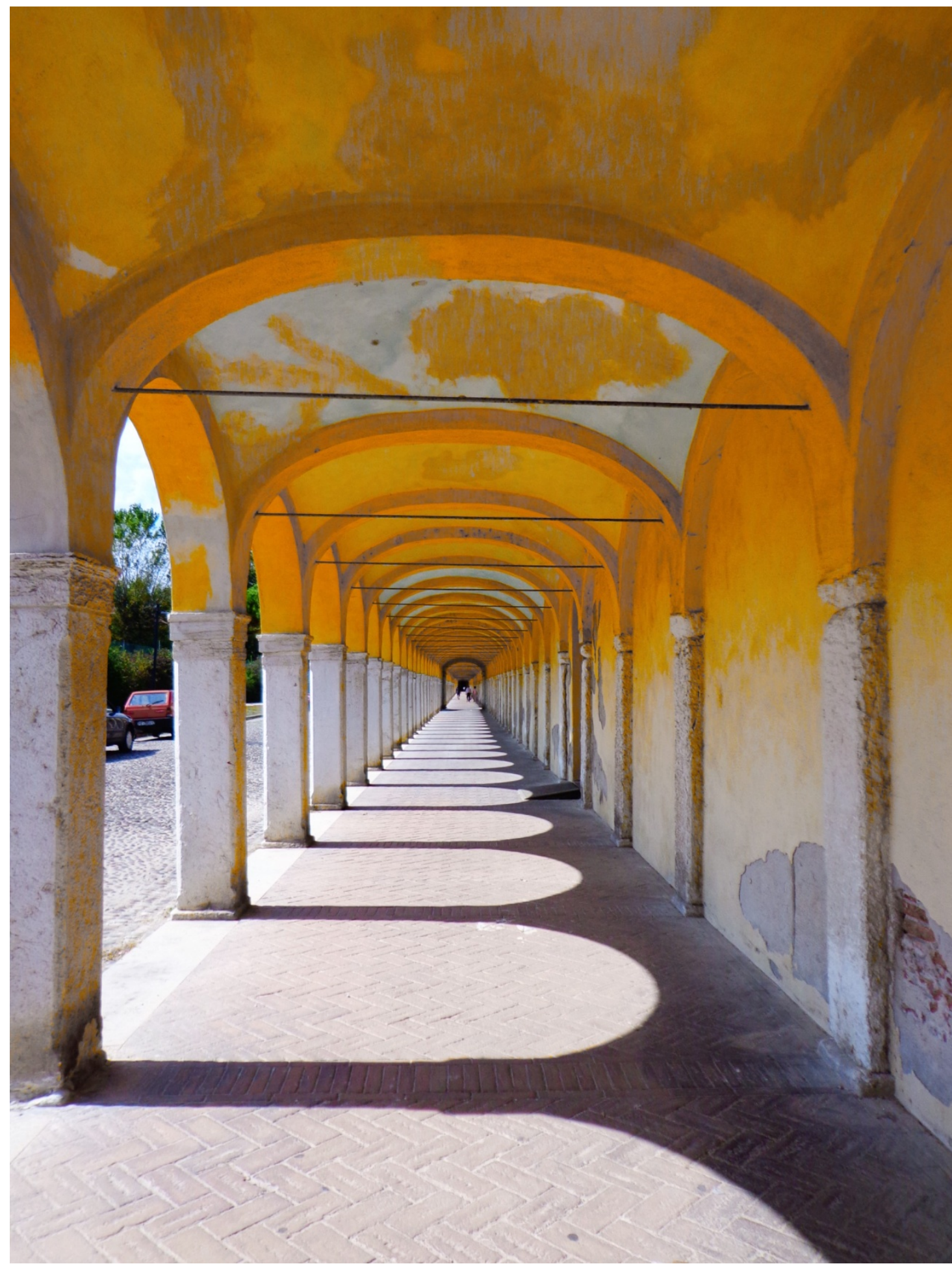


MOURE PAZOS, I ván (2016): “Apocalypse Now en la palude italiana: Comacchio en una tarde dechiriquiana". Ángulo Recto. Revista de estudios sobre la ciudad como espacio plural, vol. 8, núm. 1-2, pp. 127-137. ISSN: 1989-4015.

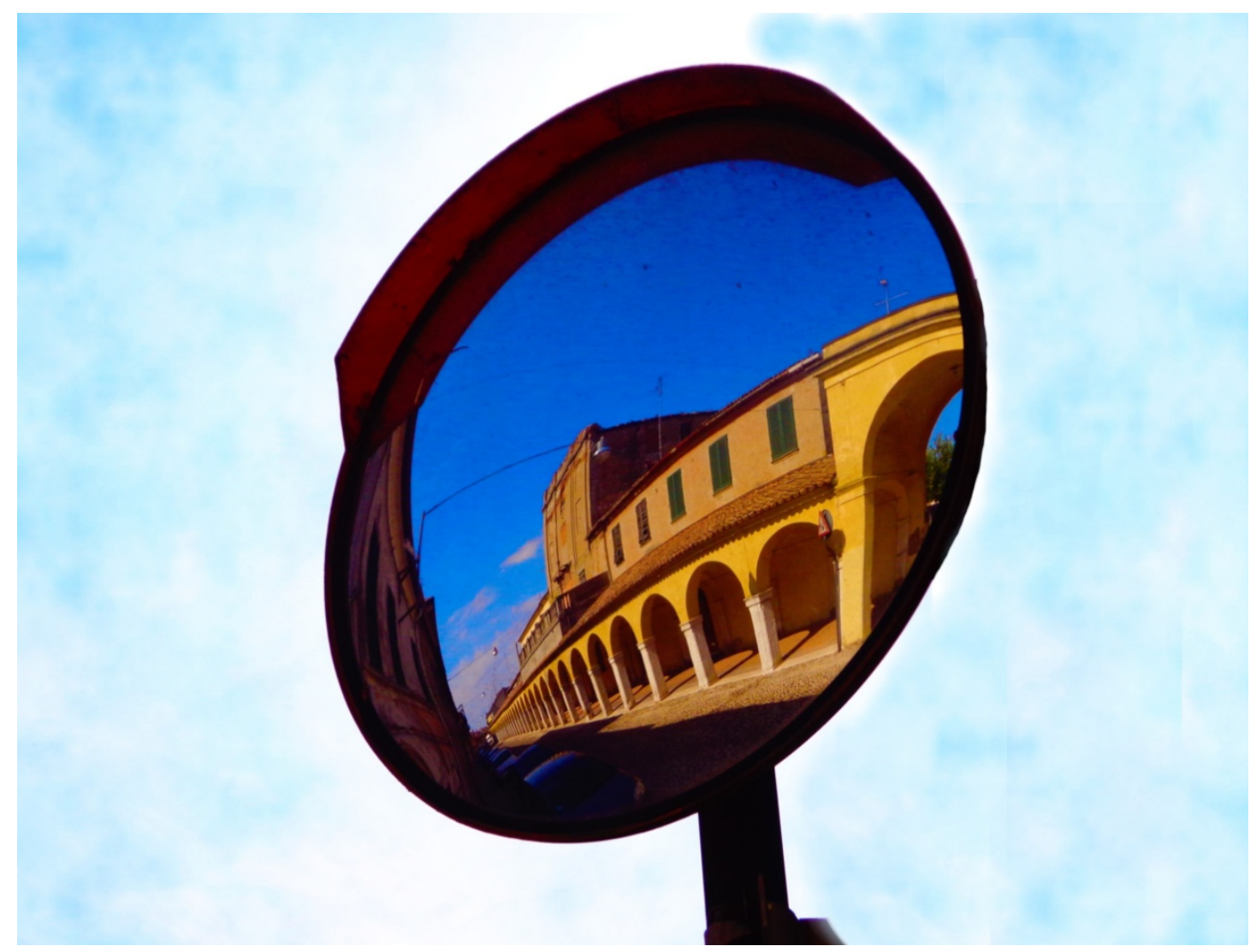

